\title{
Merkel Cell Tumor of the Thigh
}

MARY L. LINDAE, M.D.

BRIAN J. NICKOLOFF, M.D., PH.D. IRA GREENE, M.D.

\section{ARTICLE}

\begin{abstract}
This case of a Merkel cell carcinoma is unusual due to the occurrence of the tumor on the thigh; most Merkel cell tumors have been found on the sun-exposed region of the head and neck. Histologically, the nodule was composed of sheets of uniform, poorly differentiated cells with a high nuclear to cytoplasmic ratio. Electron miscroscopy revealed perinuclear filaments, scattered dense core granules; and complex, interdigitating processes within cytoplasmic membranes. Treatment consisted of surgical excision of the tumor with a wide margin.
\end{abstract}

\section{INTRODUCTION}

We report a case of Merkel cell carcinoma, ${ }^{1,2}$ also known as primary neuroendocrine carcinoma of the skin, ${ }^{3}$ located on a nonsun-exposed area of the thigh. Treatment consisted of surgical excision with a wide margin. After 3 years of follow-up, there is no evidence of tumor recurrence.

Mary L. Lindae, M.D., is Chief Resident, Stanford University School of Medicine, Department of Dermatology, Stanford, California.

Brian J. Nickoloff, M.D., Ph.D., is Assistant Professor of Pathology and Dermatology, University of Michigan Medical Center, Ann Arbor, Michigan.

Ira Greene, M.D., is Clinical Associate Professor of Dermatology, Stanford University School of Medicine, Department of Dermatology, Stanford, California; and Chief, Division of Dermatoloy, Santa Clara Valley Medical Center, San Jose, California.

Address reprint requests to Ira Greene, M.D., Santa Clara Valley Medical Center, 751 South Bascom Avenue, San Jose, CA 95128.

. J. Dermatol. Surg. Oncol. 14:4 April 1988

\section{CASE REPORT}

A 71-year-old Latin American man presented with a 2-month history of a nodule on the left medial thigh, first noted as a "purple spot" which soon enlarged and became intermittently painful when exposed to cold. There was no history of previous skin conditions. Past medical history was remarkable for noninsulin-dependent diabetes mellitus, hypertension, and a history of smoking ( 100 packs per year).

Physical examination of the skin revealed a solitary, firm, shiny, violaceous, dome-shaped nodule measuring $2.6 \times 2.3 \mathrm{~cm}$ on a papillomatous base, surrounded by a poorly demarcated, mottled, brownish-red patch measuring $8.0 \times 8.5 \mathrm{~cm}$ representing an area of contact irritant dermatitis due to a previous dressing (Fig. 1). No lymphadenopathy was detected, and the remainder of the physical examination was unremarkable. Clinical differential diagnoses included adnexal tumors, melanoma, lymphoma, and metastatic carcinoma.

Laboratory and radiologic evaluation showed no evidence of metastatic disease. Chest $x$-ray revealed two areas of increased density in the left upper lung field, clinically unchanged from previous studies and believed to represent stable granulomatous change.

Histopathologic evaluation of the skin showed focal hyperpigmentation of the basal layer but otherwise a normal epidermis. The superficial and deep dermis contained a diffuse infiltrate composed of uniform, round atypical cells with enlarged nuclei (Figs. 2 and 3 ). In some areas, the atypical cells formed cohesive nests, whereas in other areas, they were prominently discohesive. Focally, there was a 


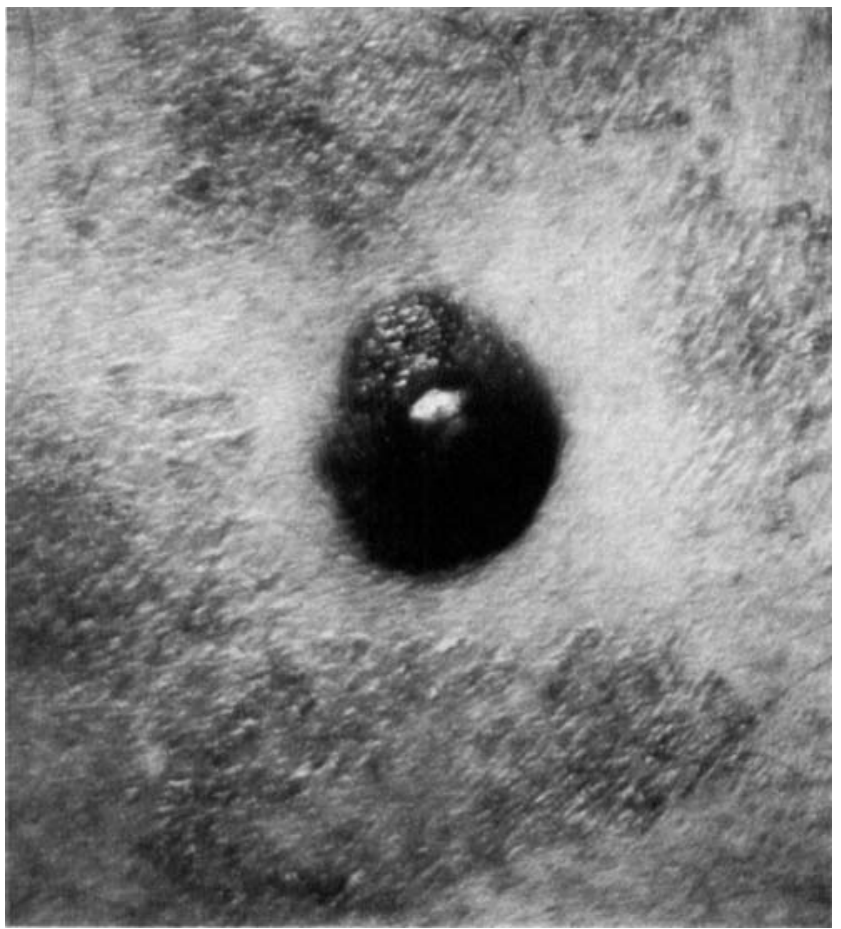

FIGURE 1. Dome-shaped nodule on left medial thigh.

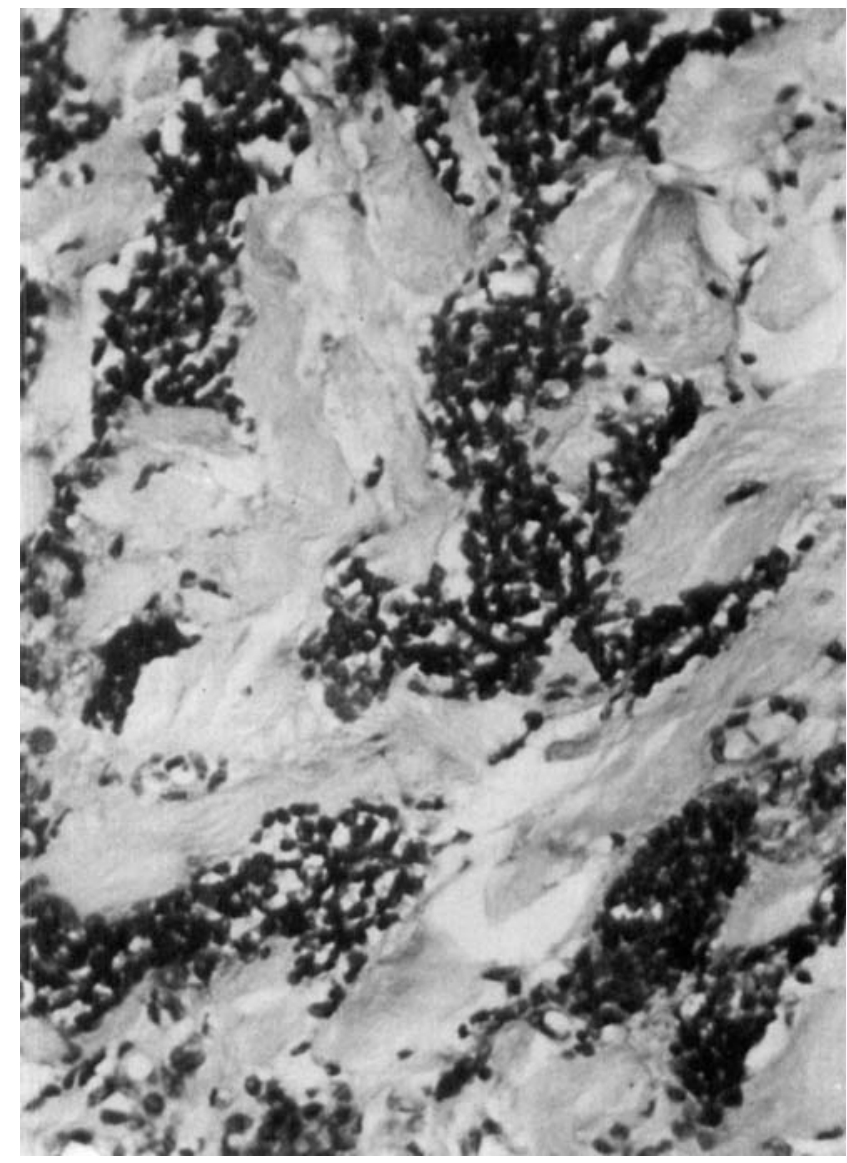

FIGURE 3. (Mid power) dense deeply invasive cords and nests of cells with hyperchromatic rounded nuclei with scant cytoplasm.

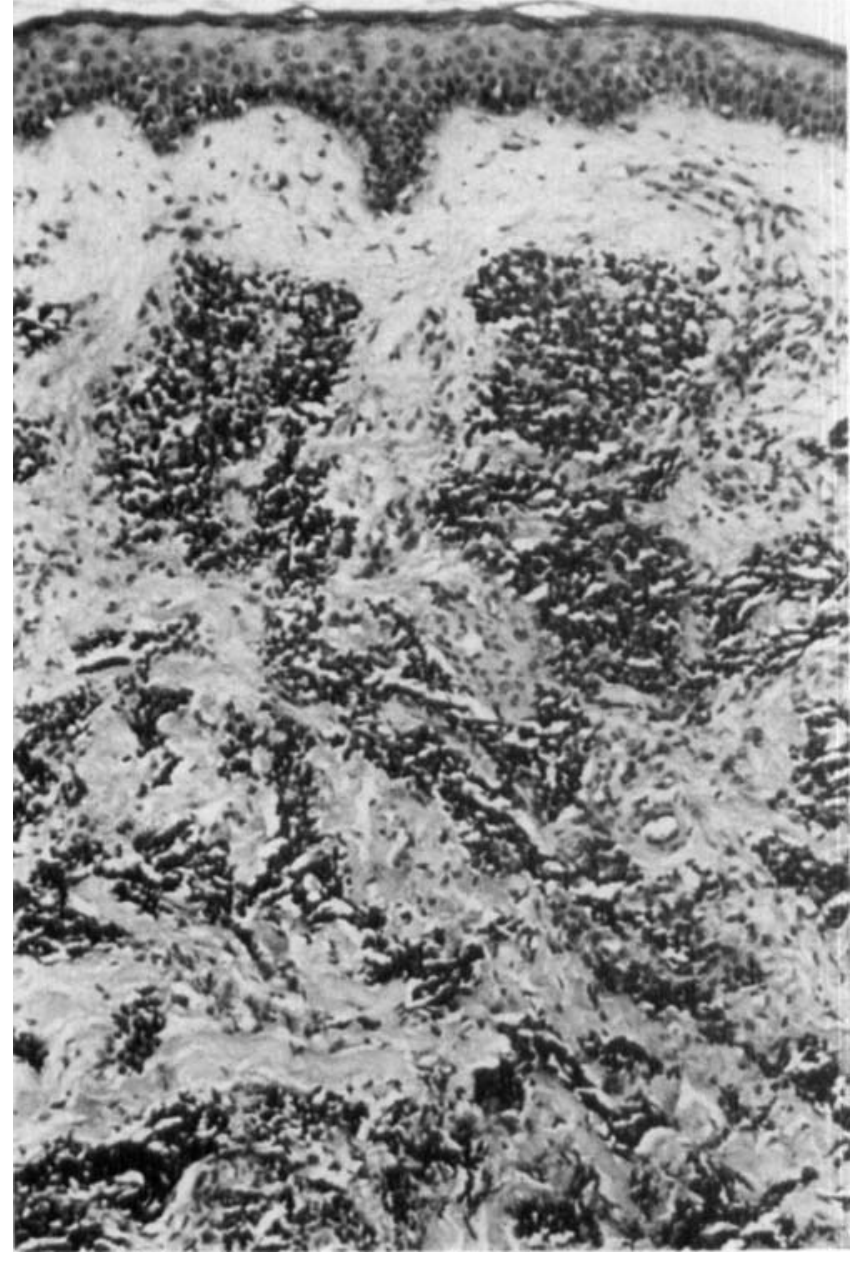

FIGURE 2. Dense diffuse dermal infiltrate of clusters and cords of round uniform cells.

suggestion of trabecular formation. Mitoses were not conspicuous (Fig. 4). The histologic differential diagnoses included malignant melanoma, adnexal tumors, neuroblastoma, lymphoma, and metastatic oat cell carcinoma. Special stains for chloracetate esterase, metachromatic granules, and pan leukocyte antigen were all negative. Tests for neuronspecific enolase and monoclonal antibodies for cytokeratin were not performed.

Ultrastructural analysis of the lesion revealed atypical cells with oval nuclei showing focal indentations and evenly dispersed chromatin. Of note, there were perinuclear filaments with focal aggregation (Fig. 5). Within the cytoplasm one found, in addition to mitochondria and golgi, scattered dense core granules. Cytoplasmic membranes showed complex interdigitating processes (Fig. 6). There were no myeloid or Birbeck granules, melanosomes, or mast cell granules seen. These findings were determined to be compatible with Merkel cell carcinoma, also known as primary neuroendocrine carcinoma of the skin.

J. Dermatol. Surg. Oncol. 14:4 April 1988 


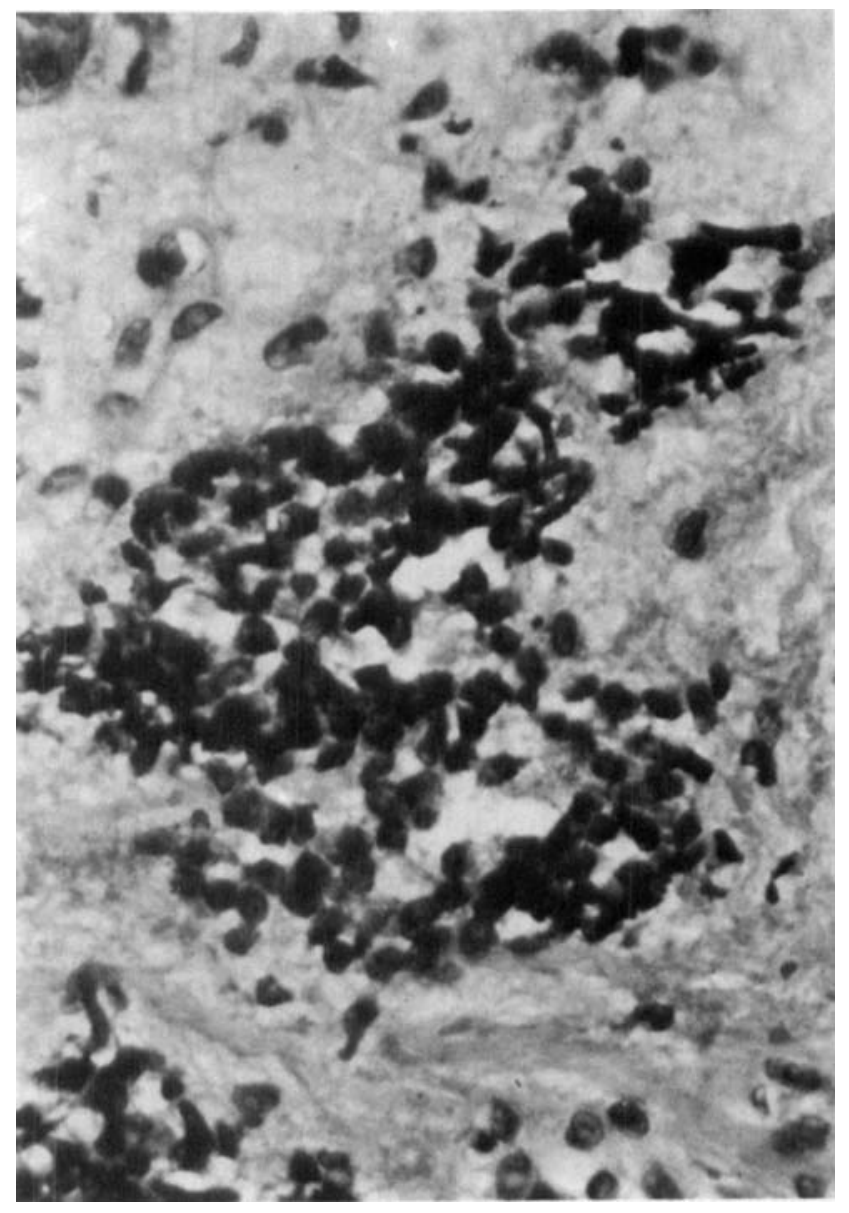

FIGURE 4. (High power) evenly dispersed heterochromatin; inconspicuous nucleoli.

\section{DISCUSSION}

Because of the similarities both histologically and ultrastructurally between Merkel cell tumors and metastatic oat cell carcinoma, several authors emphasize that all three features, namely, dense core granules, perinuclear filaments, and interdigitating processes be present before making the diagnosis of Merkel cell carcinoma. ${ }^{4}$ Other authors have been unable to find consistent, reliable, distinguishing features ultrastructurally between Merkel cell and oat cell carcinoma and stress the importance of thorough evaluation for occult malignancy before making the diagnosis of Merkel cell carcinoma. ${ }^{5}$ Ultrastructural analysis is also necessary to separate Merkel cell tumor from squamous cell carcinoma (poorly differentiated), malignant melanoma, histiocytosis $X$, and adnexal tumors (Table 1).

Treatment of the tumor consisted of surgical excision with a wide margin. After 3 years of followup, there is no evidence of tumor recurrence. Had examination of the patient revealed lymphadenop-

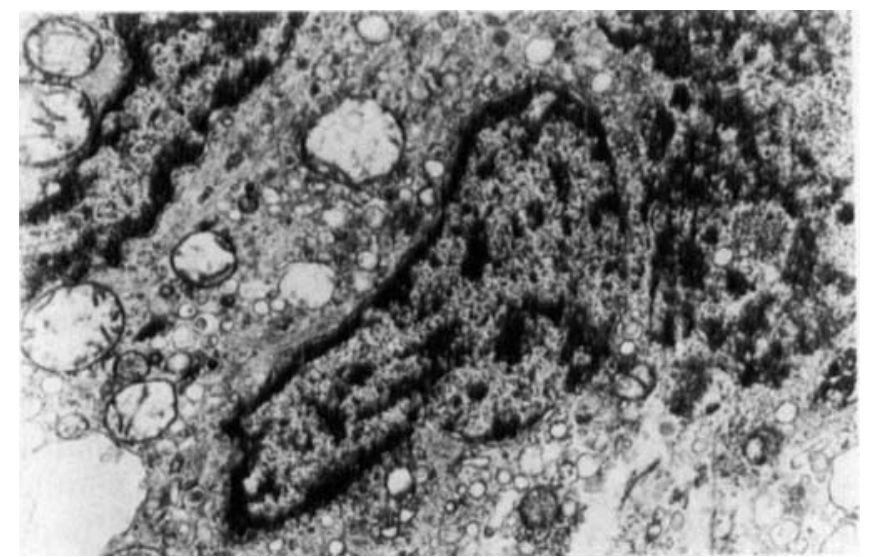

FIGURE 5. Electron microscopy of malignant cell with indented nucleus, perinuclear cytoplasmic filaments and rare membrane bound dense core granules.

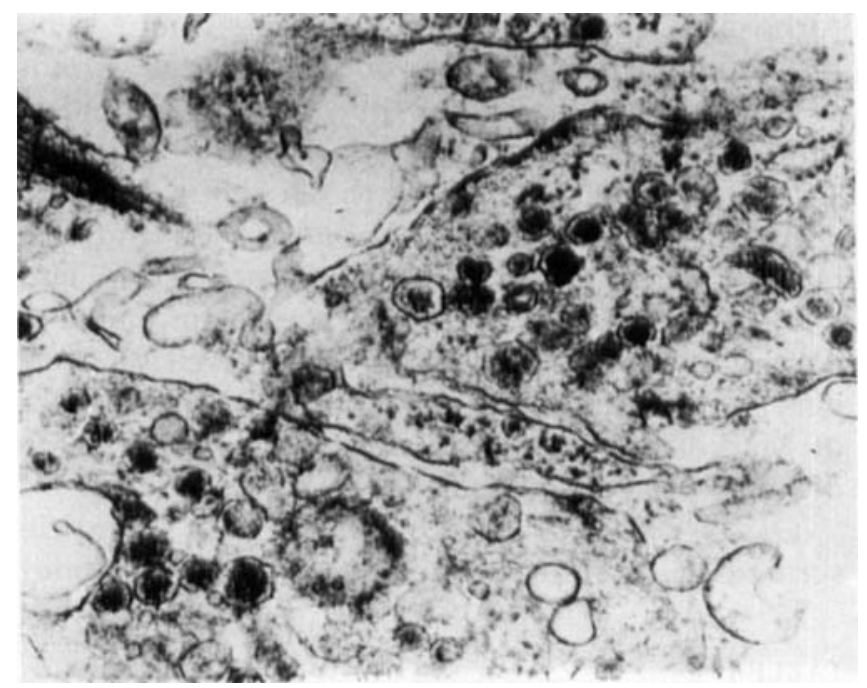

FIGURE 6. Electron microscopic appearance of elongated interdigitating spinous cytoplasmic processes containing several membrane bound dense core granules.

athy, local nodal resection and postoperative radiation therapy would have been considered.

Treatment of Merkel cell carcinoma is controversial and published studies are difficult to interpret because of the limited follow-up and variation in the modes of treatment used. Postexcision, approximately $25-65 \%$ of patients develop local or lymphatic metastases, depending on the series, and $20 \%$ die as a result of their disease. ${ }^{3,12}$ Recurrences are felt to be related to the presence of tumor close to the surgical margin. Thus, several authors emphasize the need for at least a $2 \mathrm{~mm}$ microscopic tumor-free margin in the primary excision. ${ }^{11}$

Stawowy proposes the following guidelines in the management of Merkel cell carcinoma: thorough clinical evaluation to detect the presence of 
metastatic disease, wide excision of tumor, postoperative local radiation therapy in selected cases, and regular follow-up. In the absence of lymphadenopathy, "the pathological examination of the primary tumor serves as parameter for the need for lymph node biopsy. If the primary tumor is larger than $2 \mathrm{~cm}$, contains 10 or greater mitoses per highpower-field, demonstrates evidence of lymphatic invasion or is composed of the small cell variant, a partial regional node dissection is recommended."11 The presence of lymphadenopathy makes lymph node biopsy mandatory. Should nodes prove to be positive, a radical lymph node dissection followed by radiotherapy and/or chemotherapy is recommended. In general, chemotherapy, consisting of Doxirubicin alone or in combination with cyclophosphamide or imidazole carboxamide, is recommended if the tumor is not resectable, is metastatic, is of the small cell variant, or if greater than $30 \%$ of the node is replaced by tumor. ${ }^{11}$

Roenigk et al. emphasize the need for preoperative diagnosis using both formalin-fixed and electron microscopic techniques before proceeding with definitive excision. Frozen tissue technique, employed in microscopically controlled excisional surgery, was considered inadequate for the diagnosis of Merkel cell carcinoma and thereby also in the evaluation of surgical margins. ${ }^{12}$

Of the over 100 cases of Merkel cell tumor described so far, the case presented here is moder- ately unusual as far as its location on the body. Whereas most Merkel cell tumors have been found on the head and neck in sun-exposed areas, this patient's tumor was located on the thigh in a nonsun-exposed site. In one series, 3 of 37 cases presented on the thigh. ${ }^{6}$ In all other respects, this patient's profile reflects that found in the literature for Merkel cell carcinoma, namely, late age of onset, rapid growth rate, and the histologic and ultrastructural features described above. Risk factors for this tumor have included sun exposure ${ }^{7}$ and advanced age. Males have an increased risk of developing this tumor. ${ }^{5}$

$\mathrm{O}^{\prime}$ Rourke recently reported a case of Merkel cell carcinoma that, after undergoing local metastasis, regressed spontaneously. This was felt to be the result of a cell-mediated immune phenomenon. ${ }^{8}$

Hoefler et al. demonstrated the presence in Merkel cell tumors of neuron specific enolase, cytokeratin, and neurofilament protein by immunohistochemical techniques. ${ }^{9}$ Not only may these techniques aid in the differential diagnosis (Table 2 ), but they may also point to the cell origin for these tumors. Based on early studies using these techniques, the Merkel cell tumors may be more closely related to neuroendocrine cells than to epidermal Merkel cells because of their resemblance morphologically to enteroendocrine cells of the small intestine, their location in the dermis and subcutis, and the absence in these tumors of vasoactive intestinal polypeptide (VIP) and meten-

TABLE 1

Ultrastructural Features Important in the Diagnosis of Merkel Cell Tumors

\begin{tabular}{|c|c|c|c|c|c|c|}
\hline & Desmosomes & Tonofilaments & Melanosomes & $\begin{array}{l}\text { Langerhans } \\
\text { Granules }\end{array}$ & Glycogen & $\begin{array}{c}\text { Dense Core } \\
\text { Granules }\end{array}$ \\
\hline Squamous Cell Carcinoma & + & + & - & - & - & - \\
\hline Malignant Melanoma & - & - & + & - & - & - \\
\hline Histiocytosis $X$ & - & - & - & + & - & - \\
\hline Adnexal Tumor & - & + & - & - & + & - \\
\hline Lymphoma & - & - & - & - & - & - \\
\hline Oat Cell Carcinoma & - & - & - & - & - & rare \\
\hline Merkel Cell Tumor & - & - & - & - & - & + \\
\hline
\end{tabular}

TABLE 2

Immunohistochemical Features Important in the Diagnosis of Merkel Cell Tumors

\begin{tabular}{lcccc}
\hline & $\begin{array}{c}\text { Neuron Specific } \\
\text { Enolase }\end{array}$ & Neurofilament Protein & Keratin Antigens & S 100 Protein \\
\hline Malignant Melanoma & - & - & - & + \\
Lymphoma & - & - & - & - \\
Neuroblastoma & + & - & - & - \\
Adnexal Tumor & - & - & + & - \\
Merkel Cell Tumor & + & + & + & - \\
\hline
\end{tabular}

(From Hoefler et al, 1984) 
cephalon, two markers for Merkel cells. ${ }^{10}$

In summary, Merkel cell tumor of the skin is a relatively rare neoplasm with a potentially aggressive behavior. Early diagnosis using electron microscopy, light microscopy, and immunohistochemical techniques are useful in establishing a diagnosis of Merkel cell tumor. Merkel cell tumor should be considered in the differential diagnosis of all solitary tumor nodules of the skin, whether or not they appear on sun-exposed surfaces.

\section{REFERENCES}

1. Toker C. Trabecular carcinoma of the skin. Arch Dermatol 105:107-110, 1972

2. Tang CK, Toker E. Trabecular carcinoma of the skin-an ultrasound study. Cancer 42:2311-2321, 1978

3. Wick $M$, et al. Primary neuroendocrine carcinomas of the skin (Merkel cell tumors). Amer J Clin Pathol 79:6-13, 1983.

4. Warner T, et al. Merkel cells and Merkel cell tumors. Cancer $52: 238-245,1983$.

5. Goepfert $\mathrm{H}$, et al. Merkel cell carcinoma (endocrine carcinoma of the skin) of the head and neck. Arch Otolaryngol 110:707-712, 1984

6. Sibley RK, Dahl D. Primary neuroendocrine (Merkel cell?) carcinoma of the skin. Am J Surg Pathol 9:95-108, 1985.

7. Silva G, Mackay B, Goepfert $H$, et al. Endocrine carcinoma of the skin. Pathol Ann (in press).

8. O'Rourke MGE, Bell JR. Merkel cell tumor with spontaneous regression. J Dermatol Surg Oncol 12:994-1000, 1986.

9. Hoefler $H$, et al. New immunocytochemical observations with diagnostic significance in cutaneous neuroendocrine carcinoma. Am J Dermatopathol 6:525-530, 1984

10. Friger TOB, Capella C, Ensebi E, Tenti P, Azzopardi JG. Merkel cell carcinoma of the skin: The structure and origin of normal Merkel cells. Histopathol 7:229-249, 1983.
11. Stawowy LM, Krull EA, Koich M. Merkel cell carcinoma: A challenge. J Dermatol Surg Oncol 12:443-447, 1986.

12. Roenigk RK, Goltz RW. Residents' corner: Merkel cell carcinoma-a problem with microscopically controlled surgery. J Dermatol Surg Oncol 12:332-336, 1986.

13. Berthold F, Kracht J, Lampert F, Millar TJ, Reither M, Unsicker K. Ultrastructural, biochemical and cell-culture studies of a presumed extraskeletal Ewing's sarcoma with special reference to differential diagnosis from neuroblastoma. J Cancer Res Clin Oncol 103:293-304, 1982.

14. Miettinen $M$, Lehto VP, Virtanen I. Antibodies to intermediate filament proteins: The differential diagnosis of cutaneous tumors. Arch Dermatol 121:736-741, 1985.

15. Ornvold $\mathrm{K}$, Nielsen $\mathrm{MH}$, Clausen N. Disseminated histocytosis $X$. Acta Pathol Microbiol Immunol Scand [A] $93: 311-316,1985$.

16. Wilson TS, McDowell EM, Marangos PJ, Trump BF. Histochemical studies of dense-core granulated tumors of the lung: Neuron-specific enolase as a marker for granulated cells. Arch Pathol Lab Med 109:613-620, 1985.

17. Leff EL, Brooks TS, Trojanowski JQ. Expression of neurofilament protein and neuron-specific enolase in small cell tumors of the skin using immunohistochemistry. Cancer 56:625-631, 1985 .

18. Battifora $H$, Silva EG. The use of antikeratin antibodies in the immunohistochemical distinction between neuroendocrine (Merkel cell) carcinoma of the skin, lymphoma, and oat cell carcinoma. Cancer 58:1040-1046, 1986.

19. Kyrkou KA. Immunodetection of neuron-specific enolase and keratin in cytological preparation as an aid in the differential diagnosis of lung carcinoma. Diagn Cytopathol 2:217-20, 1986

20. Van Maijen GNP, Ruiter DJ, Van Leeuwen C, Prins FA, Rietsema K, Warner SO. Cytokeratin and neurofilament in lung carcinomas. Am J Pathol 116:363-369, 1984

21. Bernal SD, Baylin SB, Sharper JH, Gazdar AF, Chen LB. Cytoskeleton associated proteins of human lung cancer cells. Cancer Res 43:1798-1808, 1983.
Development of Neuroendocrine (Merkel cell) Carcinoma Mixed with Squamous Cell Carcinoma in Erythema Ab Igne. CS Jones, SK Tyring, PC Lee, J-D Fine. Arch Dermatol 124:110-113, 1988.

The authors report a patient with co-existing invasive squamous cell carcinoma and Merkel cell carcinoma (MCC), superimposed upon erythema $a b$ igne of the leg. Routine histopathologic diagnosis was confirmed by antibody studies for cytokeratin and neuron specific enolase and by electron $\mathrm{mi}$ croscopy. Previous studies have reported a $34 \%$ concurrence rate for SCC and MCC. Some explanations have been offered to explain this co-existence: (1) A common precursor cell shows differentiation towards both keratinocytes and endocrine cells, or (2) the precursor cells of each neoplasm are affected by the same carcinogen and thus two tumors arise and co-exist.

PEARON G. LANG, JR., M.D.
Superpulse $\mathrm{CO}_{2}$ Laser Treatment of Facial Syringomata. DB Apfelberg, JR Maser, H Lash, DN White, B Cosman. Laser Surg Med 7:533-537, 1987.

Eight patients were treated as outpatients under local anesthesia. Previous treatment with continuous wave $\mathrm{CO}_{2}$ lasers had been unsuccessful. A vaporizing mode was used. Once the overlying epidermis was removed, fine forceps were used to extricate the underlying cyst. The wounds usually healed in 7-10 days although fading required 6-8 weeks. Five of six patients had good to excellent results; the remaining patient did not improve. Recurrences were uncommon. Although previous authors have reported good results with the continuous wave $\mathrm{CO}_{2}$ laser, these authors suggest that the superpulsed $\mathrm{CO}_{2}$ laser may be more effective and may cause less scarring because of the tissue vibration it creates and because less thermal damage occurs. 
EXTENDING YOUR LIMITS IN HIGH-POTENCY CORTICOSTEROID THERAPY

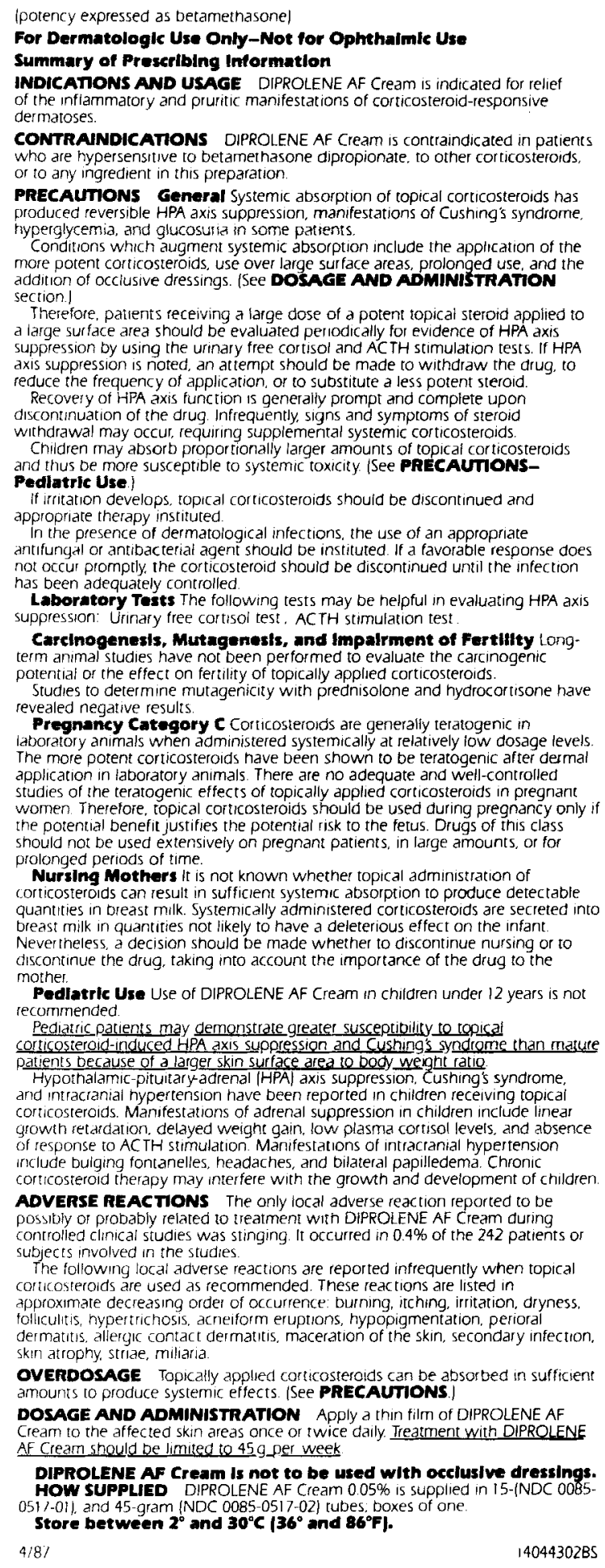

Topical Tretinoin Improves Photoaged Skin. JS Weiss, et al. JAMA 259:527-532, 1988.

This original contribution compared topical tretinoin and vehicle cream in 30 patients over a 16week period (originally 40 patients were enrolled). Treatment sites included dorsal forearms (dorsum of the hands) and the face. Forearm skin improvement was often graded as superior to that of facial skin with fine wrinkles improved in both locations. Dermatitis was reported as an adverse reaction in $92 \%$ of patients, 11 patients required potent topical steroids and 3 patients (7.5\% of the original 40 patients) withdrew as a result of the dermatitis.

As this article received widespread lay press review, it is a study of importance with other related protocols sure to follow.

HUBERT T. GREENWAY, JR., M.D.

Melanoma with Metastasis to Regional or Inguinal Lymph Nodes. SE Singletary, et al. South Med J 81:5-9, 1988.

A retrospective analysis over a 30-year interval at M.D. Anderson Hospital revealed 714 patients with melanoma who underwent node dissection for histologically positive nodes. Survival rates calculated from the date of node dissection were $33 \%$ ( 5 year) and $28 \%$ (10 year). The major prognostic factor survival was the number of positive nodes. Age, sex, race, location of the primary (except on the calf), immediate vs delayed node dissection, and adjuvant therapy were all factors unrelated to survival after the development of regional node disease.

HUBERT T. GREENWAY, JR., M.D.

Natural Interferon Alfa for Treatment of Condylomata Acuminata. AE Friedman-Kien, et al. JAMA 259:533-538, 1988.

Natural (leukocyte) interferon alfa was given twice weekly for up to 8 weeks for the treatment of condyloma acuminata (double blind, placebo controlled 72 patients) in 86 patients. Most of the patients $(>85 \%)$ had received previous therapy for their lesions. Treatment completely eliminated warts in $62 \%$ of patients (compared with $21 \%$ of placebo controls). This study indicates longer treatment regimens (than in other recent studies) may provide improved results in these patients.

HUBERT T. GREENWAY, JR., M.D. 